\title{
Massachusetts Employment Growth 1996-2006: Effects of Industry Performance and Industry Composition
}

\author{
Katharine L. Bradbury and Yolanda K. Kodrzycki
}

\begin{abstract}
:
This brief examines the effects of industry performance and industry composition on overall changes in Massachusetts employment in the period 1996 to 2006. Through 2000, Massachusetts enjoyed strong economic expansion. Around the time of the nationwide recession of 2001, however, the Massachusetts economy experienced a relatively severe setback, and the state has yet to regain as many jobs in the ensuing expansion as it lost in the downturn.

The study finds that Massachusetts industries generally experienced slower employment growth than their national counterparts in the early 2000s. The highest-flying industries of the late 1990s did "give back" some of their gains in the early 2000s, but this fact does not explain the Commonwealth's overall employment trends relative to national trends. Other, lower-growth industries in Massachusetts also underperformed relative to their national counterparts in the early 2000s, and this disparity accounts for almost all of the observed difference between Massachusetts and U.S. employment growth rates during the post-boom period.

Cutting the data differently to focus on industries that characterize the "innovation economy" in Massachusetts allows a richer interpretation of the post-boom period. The industries in key clusters identified by the Massachusetts Technology Collaborative had declining U.S. employment in the early 2000s. In addition, these industries had steeper employment losses in Massachusetts than in the nation during this period. Thus, the identity of the state's key industry clusters, as well as the comparatively poor performance of these clusters, helps to account for the weakness of employment trends in Massachusetts compared with national trends since the boom ended.
\end{abstract}

Both Katharine Bradbury and Yolanda Kodrzycki hold the title of Senior Economist and Policy Advisor at the Federal Reserve Bank of Boston. Kodrzycki is also a member of the Index Advisory Committee for the Massachusetts Technology Collaborative. Their email addresses are, respectively, katharine.bradbury@bos.frb.org and yolanda.kodrzycki@bos.frb.org.

This brief, which may be revised, is available on the web site of the Federal Reserve Bank of Boston at http://www.bos.frb.org/economic/ppb/index.htm.

The views expressed in this brief do not necessarily reflect the official position of the Federal Reserve System.

This brief is based on materials presented in a briefing to the president of the Federal Reserve Bank of Boston in February 2007. It has been updated to reflect subsequent benchmark revisions to employment data. The authors are grateful to Robert Tannenwald and Antoniya Owens for co-authoring and providing research assistance, respectively, for an earlier memorandum on a related topic, and to Jessamyn Fleming and Nelson Gerew for their research contributions.

This version: May 4, 2007 
The Massachusetts economy performed exceptionally well during the boom years in the latter half of the 1990s. Employers added 300,000 employees to their in-state payrolls between 1996 and 2001. The annualized employment growth rate during this period, 1.9 percent, was well in excess of the Commonwealth's long-term average and comparable with the concurrent gain for the nation as a whole. ${ }^{1}$ Reflecting the particularly robust expansion in the state's highpaying industries, Massachusetts real GDP grew at an annualized rate of 5.1 percent in the late 1990s to early 2000s, considerably above the national GDP growth rate of 3.4 percent. ${ }^{2}$

As the dot-com bubble burst, businesses curtailed their spending on capital equipment and software, and the national economy slipped into recession. Starting in 2001, the Massachusetts economy experienced a greater setback than most other parts of the nation. During the period when the U.S. job count was falling, Massachusetts lost a greater fraction of its jobs than any other state. National employment began to recover in August 2003, but Massachusetts continued to lose jobs for several more months, and the subsequent pickup was initially modest. As a result, Massachusetts has yet to regain as many jobs as it lost in the downturn, while the total U.S. job count stands comfortably above its previous peak. Measured from 2001 to 2006, the annualized rate of job change for the state was -0.6 percent, more than a full percentage point below the 0.7 percent national gain.

The experience of the Massachusetts economy relative to the nation as summarized above suggests two questions that are addressed in this policy brief. First, is the state's poor performance since 2001 the direct result of corrections in industries that grew unsustainably rapidly in the late 1990s? If so, then perhaps one should view the 2001 peak in state employment as an artificially high benchmark, and the poor employment performance from 2001 to 2006 as mere "payback" for the high-flying late 1990s. Second, to what degree is the Commonwealth's recent experience a reflection of job cuts in the industries that have been at the core its knowledge-based economy? If the state's key industries account for a significant

\footnotetext{
${ }^{1}$ Indicative of long-term trends, the annualized growth rate of Massachusetts payroll employment from 1969 to 1996 was 1.1 percent.

2 Owing to a break in the state GDP data associated with the conversion from SIC- to NAICS-based industries, the GDP figures are computed from 1997 to 2001.
} 
portion of the deterioration in Massachusetts employment, it becomes important to learn whether their poor performance was specific to Massachusetts or a more general phenomenon, as well as whether their retrenchment represented a structural decline or simply a temporary setback.

This brief does not attempt to project how Massachusetts economic growth is likely to compare with the national rate in coming years. However, the study can be viewed as a justification for continuing investigations into the various cyclical, structural, and locationspecific factors that affect the state's key industries.

\section{The 2001-2006 role of industries that grew fastest from 1996 to 2001}

Table 1 reports growth rates for 67 industries over the 1996-2001 period, listed in declining order of their percentage change in Massachusetts. ${ }^{3}$ Industries in the top ten during the boom include three construction categories; money management ("securities, commodity contracts, investments"); professional and technical services; Internet-related, data processing, and miscellaneous information ("other information") services; air transportation; telecommunications services; amusements, gambling, recreation; and religious/grantmaking/ civic/professional ("membership") organizations. Only four of the top ten-professional and technical services, specialty trade contractors, money management, and membership organizations - were also in the top ten in terms of absolute job gains from 1996 to 2001. (See second-from-right column in Table 1. The other six industries with the biggest job additions had more modest growth rates: social assistance, private educational services, state government, local government, food services and drinking places, and hospitals.) In eight of the Commonwealth's ten fastest-growing industries (and 16 of the top 20), employment growth in Massachusetts outpaced the national rate during the 1996-2001 period.

Only four of the top 10 fastest-growing industries between 1996 and 2001 (and 10 of the top 20) also expanded during the 2001-2006 period. Thus, the 1996-2001 fastest-growing

\footnotetext{
3 The data are based on the Current Employment Survey (CES) and pertain to annual averages for industries at roughly the three-digit NAICS level.
} 
industries typically gave back some of their apparently excessive expansion during the ensuing five years.

In order to measure the contribution of the fast-growth industries to Massachusetts job growth in the boom of the late-1990s and more recent years, we calculate the impact on job growth of simply removing the state's 10 fastest-growing industries from the statewide job totals. Thus, we calculate the growth rate of employment for the total of the other 57 industries. ${ }^{4}$

As shown in Table 2, performing this calculation for the period between 1996 and 2001 reduces the growth rate of employment in Massachusetts to 1.1 percent (from its actual growth rate of 1.9 percent). Removing these same industries from the national totals lowers the growth rate of U.S. employment to 1.5 percent (also from its actual rate of 1.9 percent). ${ }^{5}$

Performing the same calculation for the 2001-2006 interval has only minimal impact. It leaves the rate of job decline in Massachusetts unchanged at -0.6 percent, and cuts the U.S. rate of job growth very slightly-to 0.6 percent from its actual 0.7 percent. The lack of an effect on the Massachusetts growth rate indicates that the 2001-2006 give-back from the 1996-2001 fastgrowth industries represents only a small part of the explanation for the poor performance of overall employment in Massachusetts in the 2001-2006 period. These rapid-growth industries lost jobs only slightly faster than the rest of the economy (showing a 0.7 percent decline as compared with 0.6 percent), so taking them out leaves the shortfall compared with the nation essentially unchanged at 1.2 percentage points. It follows that the observed disparity between employment growth in Massachusetts and the nation in the post-boom period is almost entirely

\footnotetext{
${ }^{4}$ We caution readers that these and later calculations are meant to account for the contributions of various industries to overall job growth, but they do not represent economic simulations. The estimates assume that removing industry $X$ from the state economy has no effect on growth in industry $Y$. But, clearly, the growth rate in any given industry in Massachusetts has impacts on related industries in the state. Furthermore, the performance of industries in Massachusetts has a bearing on the performance of industries elsewhere in the nation (and vice versa). One would need to develop a detailed economic model, including input-output relationships across state-industry combinations, in order to provide more definitive measures of how the performance of various industries affected the Massachusetts economy during the past decade.

${ }^{5}$ It is to be expected that this assumption reduces the overall growth rate in Massachusetts more than it reduces the U.S. growth rate, since the industries are selected on the basis of their fast growth in Massachusetts.
} 
accounted for by the underperformance of the remaining 57 industries in Massachusetts (those that did not experience the fastest employment growth in the late 1990s).

Over the full decade from 1996 to 2006, taking these 10 fast-growth industries out of the mix in this way reduces annual employment growth in Massachusetts from 0.7 percent (actual) to 0.3 percent, and reduces the U.S. rate of job growth from 1.3 percent (actual) to 1.0 percent. In other words, without the top 10, the Commonwealth's annualized rate of employment growth in the latest decade was slower than the national figure by 0.8 percentage point, instead of by 0.6 percentage point (actual).

These calculations are repeated in the next two rows of Table 2 using the state's top 20 fastest-growing industries from the late 1990s. The results are similar, reinforcing the finding that it is not give-back from the fast-growth industries that explains the poor performance of employment in Massachusetts between 2001 and 2006. Over the 1996-2006 decade, the performance of the remaining 47 industries in Massachusetts fell short of their national counterparts by 0.8 percentage point per year, similar to the shortfall obtained by dropping just the top 10 fastest-growing industries. ${ }^{6}$ Defined either way, the industries that grew the fastest between 1996 and 2001 added more to the Commonwealth's relative growth in the boom than they subtracted in the 2001-2006 post-boom period.

\section{The role of industries more critical for Massachusetts than the nation}

So far, this analysis has focused on the contributions to Massachusetts employment growth in the past decade of industries that grew very fast in the late 1990s. Another approach is to focus on the contributions of industries that have been deemed critical in the development of the state's knowledge-based economy. To implement such an analysis, we examine employment in the 10 key industry clusters identified in the Massachusetts Technology Collaborative (MTC) Index of the Innovation Economy. Together, these clusters directly account

\footnotetext{
${ }^{6}$ The $11^{\text {th }}$ through $20^{\text {th }}$ fastest-growing industries actually added Massachusetts jobs in the 2001-2006
} period, on average. 
for about one-quarter of Massachusetts jobs, as compared with less than one-fifth of U.S. jobs. ${ }^{7}$

While the key clusters are intended to represent industry groupings that are important for the success of the Massachusetts economy, these clusters did not all add jobs rapidly during the latest boom period. The Index clusters include some of the industries that experienced very fast employment growth in the late 1990s as well as other, slower-growing industries. For example, the financial services cluster contains money management, and the software and communications services cluster contains various Internet-related and telecommunications services. As noted above, these industries were among the top 10 in terms of percentage employment expansion during the boom. On the other hand, the computer and communications hardware cluster includes the manufacture of telecommunications and other computing and electronic products, which ranked only 53 ${ }^{\text {rd }}$ in terms of 1996-2001 growth rates of the 67 industries listed in Table 1. Furthermore, some of the high-flying industries of the late 1990s - notably the construction categories and non-technical services such as amusement and recreation-are not found in any of the key clusters.

Table 3 compares employment growth for the MTC key clusters and for the sum of all remaining industries in both Massachusetts and the nation. In the 1996-2001 period, the growth rate of Massachusetts employment across all of the key clusters, 2.5 percent, outpaced these clusters' national annualized growth rate of 1.9 percent. Outside the key clusters, Massachusetts employment growth was 1.7 percent, lower than within the key clusters and also somewhat lower than the nationwide performance of these industries. These findings indicate that the MTC key-cluster industries contributed substantially to the strong economic growth experienced in Massachusetts between the mid 1990s and the early 2000s. Without these

\footnotetext{
7 The cluster definitions are formed using four-digit (rather than mostly three-digit) NAICS codes. More complete documentation and findings are available at http://masstech.org/institute/the index.htm. In order to extend the analysis back to 1996, we reconstructed data for each of the key clusters, using the U.S. Bureau of Labor Statistics Quarterly Census of Employment and Wages. This procedure resulted in some discrepancies between the employment levels used in this analysis versus those obtained from the Massachusetts Technology Collaborative for more recent years. These discrepancies appear to have little if any effect on the computed employment growth rates for the time periods analyzed. We are grateful to Robert Kispert of the Massachusetts Technology Collaborative for providing and discussing the data underlying the Index.
} 
industries, Massachusetts employment growth would have fallen short of national employment growth, other things being equal.

In the 2001-2005 period, however, the key cluster industries gave back some of their boom-period gains, shedding jobs in Massachusetts at an above-average pace. ${ }^{8}$ The rest of the Massachusetts economy experienced only a modest change in employment of -0.2 percent, as compared with the actual all-industries 1.0 percent rate of decline. Dropping the key clusters raises employment growth nationally only slightly - to 0.7 percent (from its actual all-industries rate of 0.4 percent). Thus, declines in employment within the key clusters dragged down employment growth in the Commonwealth more substantially than in the nation.

The greater negative impact on Massachusetts is a result of both the relatively high concentration of these (U.S.-job-losing) clusters in Massachusetts, and of the faster rate of employment decrease in the key clusters in Massachusetts than in the nation during the 20012005 period. In Massachusetts, cluster employment fell at a rate of 3.2 percent in the first half of the 2000s - totally offsetting the clusters' employment increases in the latter 1990s through 2001. For the nation, cluster employment fell at a rate of only 1.3 percent in the 2001-2005 period.

This exercise shows that the relatively steep losses in key-cluster industries help to explain the Commonwealth's poor performance in the 2001-2005 period. These ten industry clusters account for 0.4 percentage point of the total shortfall of 1.3 percentage points in the Massachusetts employment growth rate relative to the nation's. Below-average Massachusetts employment growth in non-cluster industries (slightly declining MA employment compared to positive U.S. growth for these industries nationwide) accounts for the remaining 0.9 percentage point shortfall.

For the 1996-2005 period as a whole, the differential between Massachusetts and U.S. employment growth rates was the same overall as outside the clusters. The clusters grew more slowly than non-cluster industries, but this was the case in both Massachusetts and the nation. Thus, the comparatively slower employment growth of the clusters in Massachusetts does not

\footnotetext{
8 Data on cluster employment are not yet available for all of 2006, so the post-boom period for the cluster analysis refers to 2001-2005, not 2001-2006 as in section I above.
} 
account for any of the 0.6 percentage point gap between the overall Massachusetts and U.S. employment growth rates over the full nine-year timeframe.

\section{III . Summary of Findings}

The first question we set out to answer is whether the state's poor performance since 2001 is the direct result of corrections in industries that grew unsustainably rapidly in the late 1990s. In general, Massachusetts industries experienced slower employment growth than their national counterparts in the early 2000s. The highest-flying industries of the late 1990s did give back some of their gains in the early 2000s, but this fact does not explain the Commonwealth's employment trends relative to the nation. Other, lower-growth industries in Massachusetts also underperformed relative to their national counterparts in the early 2000s, and this disparity accounts for almost all of the observed difference between Massachusetts and U.S. employment growth rates in the post-boom period.

Our second question focuses on the role of key, innovation-oriented industries (those included in the Massachusetts Technology Collaborative Index of the Innovation Economy) in explaining the Commonwealth's employment deterioration in the post-boom period. These industries experienced declining U.S. employment in the early 2000s. In addition, they had steeper employment losses in Massachusetts than nationally during this period. Thus, the identity of the state's key clusters and the comparatively poor performance of these clusters both help to account for the weakness of the state's employment trends relative to the nation's since the boom ended. Together, the ten industry clusters examined account for 0.4 percentage point of the total shortfall of 1.3 percentage points in the Commonwealth's annualized employment growth rate as compared with the nation's from 2001 to 2005 . The rest of the shortfall is due to below-average growth in the rest of the Massachusetts economy (non-cluster industries).

In summary, the study rejects a simple "payback for the high-flying 1990s" view of the lackluster employment trends in Massachusetts since 2001. Removing the fastest-growing industries of the latter 1990s from the growth calculation does not narrow the gap between Massachusetts and U.S. employment growth in the 2000s to date-that is, the rest of the 
Massachusetts economy has lost jobs at the same pace as these formerly strong-growth industries. The study instead supports the view that steeper employment losses in the state's key industries - which overlap only partly with the industries that grew the fastest between 1996 and 2001-contributed to the state's relative slowdown, along with below-U.S.-average employment growth across non-cluster industries. We find that in the second half of the 1990s, the key clusters grew somewhat faster in Massachusetts than in the nation, but that their employment declines in the first half of the 2000s were steeper than in other industries, and steeper in Massachusetts than in the nation as a whole.

Beyond the insights they yield on the post-boom period, these results serve to define a framework for thinking about how industry performance and industry composition might affect the future development of the Massachusetts economy. In looking forward, the state's leaders should consider how best to bridge the gap between Massachusetts and U.S. industry growth rates and, in particular, the gap between the growth rates of the key clusters in Massachusetts and their growth rates in other locations. Gaining a better understanding of these industries' comparatively poor performance in Massachusetts during the early 2000s would be an important step in such deliberations. The state's leaders may also want to consider whether other, as yet unidentified, industries can play a critical role in the further development of the state's innovation economy, in view of the finding that the key clusters had lower job growth than other industries in the 1996-2005 period in both Massachusetts and the nation,. 
Table 1. Employment Change 1996-2006, Industries Sorted on MA Annual Job Growth Rate Between 1996 and 2001

\begin{tabular}{|c|c|c|c|c|c|c|c|c|c|}
\hline \multirow{3}{*}{$\begin{array}{c}\text { growth } \\
\text { rank }\end{array}$} & & \multicolumn{3}{|c|}{ MA annual growth rate (\%) } & \multicolumn{3}{|c|}{ U.S. annual growth rate (\%) } & \multicolumn{2}{|c|}{$\begin{array}{l}\text { MA change in number } \\
\text { of jobs (000) }\end{array}$} \\
\hline & & boom & post-boom & full period & boom & post-boom & full period & boom & post-boom \\
\hline & & 1996-2001 & 2001-2006 & 1996-2006 & 1996-2001 & 2001-2006 & 1996-2006 & 1996-2001 & 2001-2006 \\
\hline & Total Nonfarm Payrolls & 1.9 & -0.6 & 0.7 & 1.9 & 0.7 & 1.3 & 299.9 & -95.9 \\
\hline 1 & Heavy and Civil Engineering Construction & 9.3 & -7.1 & 0.8 & 3.6 & 0.6 & 2.1 & 6.6 & -5.7 \\
\hline 2 & Specialty Trade Contractors & 8.0 & 1.0 & 4.4 & 5.0 & 2.7 & 3.9 & 29.0 & 4.5 \\
\hline 3 & Construction of Buildings & 7.3 & 1.9 & 4.6 & 2.9 & 2.6 & 2.7 & 8.9 & 3.0 \\
\hline 4 & Securities, Commodity Contracts, Investments & 6.6 & -2.7 & 1.9 & 7.1 & -0.3 & 3.3 & 15.0 & -6.9 \\
\hline 5 & Professional and Technical Services & 6.3 & -0.3 & 3.0 & 5.3 & 1.3 & 3.3 & 64.2 & -3.1 \\
\hline 6 & Other Information Services & 5.5 & -5.8 & -0.3 & 5.2 & -2.0 & 1.5 & 7.6 & -8.3 \\
\hline 7 & Air Transportation & 5.5 & -8.0 & -1.5 & 3.2 & -4.6 & -0.8 & 2.8 & -4.1 \\
\hline 8 & Telecommunications & 5.3 & -6.1 & -0.5 & 5.5 & -5.7 & -0.2 & 6.6 & -7.8 \\
\hline 9 & Amusements, Gambling and Recreation & 4.8 & 2.6 & 3.7 & 3.7 & 1.1 & 2.4 & 6.0 & 3.9 \\
\hline 10 & Membership Associations \& Organizations & 4.7 & 1.4 & 3.1 & 2.8 & 1.1 & 2.0 & 10.9 & 3.9 \\
\hline 11 & Services to Buildings and Dwellings & 4.3 & 1.4 & 2.8 & 3.4 & 2.3 & 2.8 & 8.9 & 3.3 \\
\hline 12 & Building Material and Garden Supply Stores & 4.3 & 2.0 & 3.1 & 2.7 & 2.8 & 2.8 & 4.8 & 2.7 \\
\hline 13 & Other Real Estate & 4.0 & -0.4 & 1.7 & 6.7 & 0.1 & 3.3 & 0.1 & 0.0 \\
\hline 14 & Social Assistance & 3.7 & 1.1 & 2.4 & 5.2 & 3.5 & 4.3 & 9.7 & 3.4 \\
\hline 15 & Furniture and Home Furnishings Stores & 3.6 & 1.1 & 2.3 & 2.7 & 1.7 & 2.2 & 2.0 & 0.7 \\
\hline 16 & Other Transp \& Warehousing & 2.8 & -1.4 & 0.7 & 2.2 & 1.5 & 1.8 & 4.4 & -2.3 \\
\hline 17 & Repair and Maintenance & 2.7 & -1.2 & 0.7 & 2.0 & -0.1 & 1.0 & 3.5 & -1.6 \\
\hline 18 & Natural Resources and Mining & 2.5 & 3.8 & 3.1 & -1.0 & 2.4 & 0.7 & 0.2 & 0.3 \\
\hline 19 & Sporting Goods, Hobby, Book and Music Stores & 2.4 & -1.7 & 0.3 & 2.0 & -1.0 & 0.5 & 2.2 & -1.6 \\
\hline 20 & Motor Vehicle and Parts Dealers & 2.4 & 0.3 & 1.3 & 1.9 & 0.6 & 1.2 & 4.0 & 0.5 \\
\hline 21 & Transit \& Ground Passenger Transportation & 2.4 & -0.2 & 1.1 & 2.0 & 1.0 & 1.5 & 1.9 & -0.2 \\
\hline 22 & Other Arts, Entertainment, and Recreation & 2.3 & 1.8 & 2.0 & 3.6 & 1.0 & 2.3 & 1.4 & 1.2 \\
\hline 23 & Personal and Laundry Services & 2.3 & 0.5 & 1.4 & 1.5 & 0.5 & 1.0 & 3.8 & 0.8 \\
\hline 24 & Real Estate & 2.2 & 1.4 & 1.8 & 2.1 & 2.3 & 2.2 & 3.0 & 2.2 \\
\hline 25 & Private Educational Services & 2.2 & 1.4 & 1.8 & 3.9 & 3.1 & 3.5 & 14.8 & 10.5 \\
\hline 26 & Accommodation & 2.1 & -1.5 & 0.3 & 1.7 & -0.2 & 0.8 & 3.6 & -2.6 \\
\hline 27 & Truck Transportation & 2.1 & -1.2 & 0.5 & 1.6 & 0.7 & 1.1 & 1.7 & -1.0 \\
\hline 28 & Publishing Industries ex Internet & 2.1 & -3.5 & -0.8 & 1.9 & -2.4 & -0.3 & 5.0 & -8.3 \\
\hline 29 & Management of Companies and Enterprises & 2.0 & -2.9 & -0.5 & 0.9 & 0.3 & 0.6 & 6.8 & -10.0 \\
\hline 30 & Wholesale, Durable Goods & 1.9 & -2.9 & -0.5 & 1.0 & -0.3 & 0.3 & 6.7 & -10.2 \\
\hline 31 & $\begin{array}{l}\text { Credit Intermediation and Related Activities } \\
\text {...table continued }\end{array}$ & 1.9 & 0.9 & 1.4 & 1.9 & 2.5 & 2.2 & 5.4 & 2.8 \\
\hline
\end{tabular}

Source: Authors' calculations based on U.S. Bureau of Labor Statistics employment data, CES series; annual averages of unadjusted data. 


\begin{tabular}{|c|c|c|c|c|c|c|c|c|c|}
\hline \multirow{3}{*}{$\begin{array}{l}\text { growth } \\
\text { rank }\end{array}$} & & \multicolumn{3}{|c|}{ MA annual growth rate } & \multicolumn{3}{|c|}{ U.S. annual growth rate (\%) } & \multicolumn{2}{|c|}{$\begin{array}{c}\text { MA change in number } \\
\text { of jobs }(000)\end{array}$} \\
\hline & & boom & post-boom & full period & boom & post-boom & full period & boom & post-boom \\
\hline & & 1996-2001 & 2001-2006 & 1996-2006 & 1996-2001 & 2001-2006 & 1996-2006 & 1996-2001 & 2001-2006 \\
\hline 32 & Wholesale, Nondurable Goods & 1.9 & 0.8 & 1.3 & 0.5 & 0.1 & 0.3 & 4.2 & 1.8 \\
\hline 33 & State Government & 1.9 & -0.7 & 0.6 & 1.3 & 0.7 & 1.0 & 10.5 & -3.9 \\
\hline 34 & Local Government & 1.8 & -0.2 & 0.8 & 2.2 & 1.1 & 1.6 & 22.4 & -2.4 \\
\hline 35 & Rental and Leasing Services & 1.7 & -3.4 & -0.9 & 2.5 & -0.6 & 1.0 & 1.2 & -2.3 \\
\hline 36 & Miscellaneous Manufacturing & 1.7 & -5.1 & -1.8 & 0.0 & -1.8 & -0.9 & 2.5 & -7.1 \\
\hline 37 & Food Services and Drinking Places & 1.7 & 1.3 & 1.5 & 2.0 & 2.3 & 2.2 & 16.5 & 13.2 \\
\hline 38 & Health and Personal Care Stores & 1.7 & 0.4 & 1.0 & 2.9 & 0.1 & 1.5 & 2.1 & 0.5 \\
\hline 39 & Hospitals & 1.5 & 3.1 & 2.3 & 1.4 & 1.8 & 1.6 & 10.2 & 23.0 \\
\hline 40 & Miscellaneous Store Retailers & 1.4 & -3.3 & -1.0 & 2.6 & -2.3 & 0.1 & 1.7 & -3.8 \\
\hline 41 & Employment Services & 1.3 & -0.7 & 0.3 & 5.7 & 1.2 & 3.5 & 4.1 & -2.1 \\
\hline 42 & General Merchandise Stores & 1.3 & -0.4 & 0.4 & 1.4 & 0.5 & 0.9 & 2.6 & -0.9 \\
\hline 43 & Insurance Carriers and Related Activities & 1.2 & -0.8 & 0.2 & 1.2 & 0.7 & 0.9 & 4.0 & -2.5 \\
\hline 44 & Other Admin and Waste & 1.0 & -0.5 & 0.2 & 2.3 & 1.2 & 1.7 & 2.7 & -1.4 \\
\hline 45 & Chemical Manufacturing & 0.7 & -1.5 & -0.4 & -0.5 & -2.0 & -1.2 & 0.7 & -1.3 \\
\hline 46 & Food and Beverage Stores & 0.6 & -0.7 & -0.1 & 0.2 & -0.8 & -0.3 & 2.6 & -3.2 \\
\hline 47 & Electronics and Appliance Stores & 0.4 & -0.3 & 0.1 & 3.4 & -0.6 & 1.4 & 0.3 & -0.2 \\
\hline 48 & Other Durable Goods & 0.4 & -3.8 & -1.7 & -0.1 & -2.2 & -1.2 & 0.4 & -4.4 \\
\hline 49 & Nursing \& Residential Care Facilities & 0.2 & 1.0 & 0.6 & 2.4 & 1.6 & 2.0 & 1.0 & 4.5 \\
\hline 50 & Clothing and Clothing Accessories Stores & 0.1 & 0.0 & 0.1 & 1.6 & 1.7 & 1.7 & 0.3 & 0.0 \\
\hline 51 & Electrical Equipment and Appliance Mfg & -0.2 & -6.5 & -3.4 & -1.2 & -4.8 & -3.0 & -0.1 & -4.5 \\
\hline 52 & Food Manufacturing & -0.2 & -0.1 & -0.1 & -0.1 & -0.9 & -0.5 & -0.2 & -0.1 \\
\hline 53 & Computer \& Electronic Product Manufacturing & -0.2 & -6.9 & -3.6 & 0.0 & -5.5 & -2.8 & -1.2 & -30.4 \\
\hline 54 & Other Retail & -0.5 & -2.3 & -1.4 & 0.2 & -1.5 & -0.7 & -0.7 & -2.9 \\
\hline 55 & Federal Civilian & -0.6 & -1.9 & -1.3 & -0.8 & -0.3 & -0.5 & -1.6 & -5.0 \\
\hline 56 & Other Wholesale & -0.6 & 3.3 & 1.3 & 1.5 & 5.0 & 3.3 & -0.7 & 3.8 \\
\hline 57 & Transportation Equipment Manufacturing & -1.1 & -2.3 & -1.7 & -0.4 & -1.9 & -1.1 & -0.9 & -1.8 \\
\hline 58 & Plastics and Rubber Products & -1.4 & -5.3 & -3.3 & -0.5 & -2.3 & -1.4 & -1.5 & -4.9 \\
\hline 59 & Ambulatory health care services & -1.5 & 1.6 & 0.0 & 2.5 & 3.4 & 3.0 & -9.5 & 9.7 \\
\hline 60 & Paper Manufacturing & -1.6 & -6.4 & -4.0 & -1.8 & -4.1 & -2.9 & -1.4 & -4.9 \\
\hline 61 & Printing and Related Support Activities & -1.8 & -4.1 & -2.9 & -1.2 & -3.7 & -2.5 & -1.8 & -3.7 \\
\hline 62 & Fabricated Metal Product Manufacturing & -1.9 & -3.8 & -2.9 & 0.3 & -1.5 & -0.6 & -4.3 & -7.6 \\
\hline 63 & Utilities & -2.5 & -3.6 & -3.0 & -1.3 & -1.8 & -1.5 & -1.6 & -1.9 \\
\hline 64 & Machinery Manufacturing & -2.8 & -7.8 & -5.3 & -1.4 & -2.7 & -2.1 & -4.7 & -10.0 \\
\hline 65 & Textile Mills & -3.2 & -10.6 & -7.0 & -5.6 & -10.1 & -7.9 & -2.0 & -4.8 \\
\hline 66 & Other Finance and Insurance & -5.9 & -1.7 & -3.8 & 4.7 & 0.6 & 2.6 & -1.3 & -0.3 \\
\hline 67 & Other Non-Durable Goods & -7.5 & -5.4 & -6.4 & -6.1 & -6.1 & -6.1 & -7.8 & -4.0 \\
\hline
\end{tabular}

Source: Authors' calculations based on U.S. Bureau of Labor Statistics employment data, CES series; annual averages of unadjusted data. 
Table 2 Contributions of Massachusetts' Fastest-Growing "Boom" Industries to Annual Employment Growth Rates, 1996-2006

\begin{tabular}{|c|c|c|c|c|c|c|c|c|c|}
\hline & \multicolumn{3}{|c|}{ MA annual growth rate (\%) } & \multicolumn{3}{|c|}{ U.S. annual growth rate (\%) } & \multicolumn{3}{|c|}{$\begin{array}{l}\text { MA-U.S. difference } \\
\text { (percentage points) }\end{array}$} \\
\hline & boom & post-boom & full period & boom & post-boom & full period & boom & post-boom & full period \\
\hline & & & 1996-2006 & & 2001-2006 & 1996-2006 & & 2001-2006 & 1996-2006 \\
\hline Total Nonfarm Employment & 1.9 & -0.6 & 0.7 & 1.9 & 0.7 & 1.3 & 0.0 & -1.2 & -0.6 \\
\hline 10 Fastest-Growing Industries & 6.4 & -0.7 & 2.8 & 4.6 & 0.9 & 2.7 & 1.8 & -1.6 & 0.1 \\
\hline Remaining 57 Industries & 1.1 & -0.6 & 0.3 & 1.5 & 0.6 & 1.0 & -0.4 & -1.2 & -0.8 \\
\hline 20 Fastest-Growing Industries & 5.4 & -0.4 & 2.5 & 3.9 & 1.2 & 2.5 & 1.5 & -1.5 & 0.0 \\
\hline Remaining 47 Industries & 0.8 & -0.7 & 0.1 & 1.3 & 0.5 & 0.9 & -0.5 & -1.1 & -0.8 \\
\hline \multirow[t]{2}{*}{ Memo: Share of total jobs (\%): } & \multicolumn{3}{|c|}{ Massachusettts } & \multicolumn{3}{|c|}{ United States } & & & \\
\hline & 1996 & 2001 & 2006 & 1996 & 2001 & 2006 & & & \\
\hline 10 Fastest-Growing Industries & 14.3 & 17.7 & 17.6 & 14.6 & 16.6 & 16.8 & & & \\
\hline Remaining 57 Industries & 85.7 & 82.3 & 82.4 & 85.4 & 83.4 & 83.2 & & & \\
\hline 20 Fastest-Growing Industries & 21.7 & 25.6 & 25.9 & 23.2 & 25.4 & 26.1 & & & \\
\hline Remaining 47 Industries & 78.3 & 74.4 & 74.1 & 76.8 & 74.6 & 73.9 & & & \\
\hline
\end{tabular}

Note: Fastest-growing industries are defined in terms of growth rates between 1996 and 2001; see Table 1.

Source: Authors' calculations based on U.S. Bureau of Labor Statistics employment data, CES series; annual averages of unadjusted data. 
Table 3 Contributions of MTC Key Industry Clusters to Annual Employment Growth Rates, 1996-2005

\begin{tabular}{|c|c|c|c|c|c|c|c|c|c|}
\hline & \multicolumn{3}{|c|}{ MA annual growth rate (\%) } & \multicolumn{3}{|c|}{ U.S. annual growth rate (\%) } & \multicolumn{3}{|c|}{$\begin{array}{l}\text { MA-U.S. difference } \\
\text { (percentage points) }\end{array}$} \\
\hline & 1996-2001 & $2001-2005$ & 1996-2005 & 1996-2001 & 2001-2005 & 1996-2005 & 1996-2001 & 2001-2005 & 1996-2005 \\
\hline MTC Key Industry Clusters & 2.5 & -3.2 & -0.1 & 1.9 & -1.3 & 0.5 & 0.6 & -1.9 & -0.5 \\
\hline \multicolumn{10}{|l|}{ Computer \& Communications } \\
\hline Hardware & -0.5 & -9.5 & -4.6 & 0.3 & -8.6 & -3.7 & -0.8 & -1.0 & -0.9 \\
\hline \multicolumn{10}{|l|}{ Defense manufacturing \& } \\
\hline Diversified Industrial Support & -1.8 & -6.9 & -4.1 & -1.1 & -3.9 & -2.3 & -0.7 & -3.0 & -1.8 \\
\hline Financial Services & 5.1 & -1.5 & 2.1 & 1.9 & 0.3 & 1.2 & 3.2 & -1.8 & 0.9 \\
\hline Healthcare Technology & 0.8 & -2.7 & -0.7 & 1.5 & 0.4 & 1.0 & -0.7 & -3.0 & -1.7 \\
\hline \multicolumn{10}{|l|}{ Scientific, Technical \& } \\
\hline Management Services & 6.2 & 2.3 & 4.4 & 5.1 & 2.6 & 4.0 & 1.0 & -0.3 & 0.4 \\
\hline Business Services & 2.9 & -0.9 & 1.2 & 3.8 & 0.6 & 2.4 & -0.9 & -1.5 & -1.2 \\
\hline Total Less Key Clusters & 1.7 & -0.2 & 0.8 & 2.0 & 0.7 & 1.4 & -0.3 & -0.9 & -0.6 \\
\hline \multirow[t]{2}{*}{ Memo: Share of total jobs $(\%)^{1}$ : } & \multicolumn{3}{|c|}{ Massachusetts } & \multicolumn{3}{|c|}{ United States } & & & \\
\hline & 1996 & 2001 & 2005 & 1996 & 2001 & 2005 & & & \\
\hline MTC Key Industry Clusters & 26.3 & 27.1 & 24.7 & 19.8 & 19.7 & 18.5 & & & \\
\hline Total Less Key Clusters & 73.7 & 72.9 & 75.3 & 80.2 & 80.3 & 81.5 & & & \\
\hline
\end{tabular}

${ }^{1}$ Total employment is CES total nonfarm employment, as in Table 2.

Source: Authors' calculations based on U.S. Bureau of Labor Statistics employment data, CES series and

Quarterly Census of Employment and Wages; annual averages of unadjusted data. 